\title{
UN ESCENARIO PRIVILEGIADO PARA LAS FIESTAS DEL APÓSTOL SANTIAGO: LA PLAZA DEL OBRADOIRO
}

\author{
por \\ FERNANDO PÉREZ RODRÍGUEZ
}

Bajo la denominación de fiestas del Apóstol se comprenden muchos actos públicos como pueden ser los juegos de cañas, torneos, representación de comedias, procesiones, quema del «castillo de fuego», fuegos artificiales y la corrida de toros. La necesidad de un espacio amplio y cómodo para la mayoría de estos actos determinará la elección de la Plaza del Obradoiro como el escenario más apropiado, convirtiéndola en el espacio por excelencia de la fiesta.

La historia del Hospital Real está marcada por constantes pleitos o litigios entre sus administradores y distintas personalidades e instituciones de la ciudad de Santiago. El que ahora analizamos tiene lugar en los años 1745 a 1747 y sus protagonistas son el administrador del Hospital y la ciudad de Santiago. El motivo es la colocación de «talanqueras» delante de la fachada principal del Hospital Real para presenciar la corrida de toros, algo que, además de ser desconsiderado por dar las espaldas a un edificio regio, les impedía la visión del espectáculo desde sus balcones. El trasfondo es interesante ya que están en juego los «derechos de posesión» de la plaza'.

\footnotetext{
1 Todos los documentos referidos en este trabajo, que no llevan su propia cita, se conservan en el Archivo Histórico Nacional, Sección de Consejos, Legajo 17.207.
}

"CUADERNOS DE ESTUdIOS GALLEGOS", Tomo XLII, Fasciculo 107, Santiago 1995. 
Pero antes de continuar con este pleito es necesario puntualizar algunos aspectos sobre este tipo de festejos, a los que incluso se le quiso dar una justificación cultural a juzgar por la argumentación que la propia ciudad da de estos espectáculos: «esta funzion dice Alusion Sagrada a los Toros que de Yria Flavia, aora villa de Padron; condujeron a Compostela su sagrado Apostolico Cuerpo; y casi desde su maravillosa ymbencion se continua $)^{2}$. La celebración taurina vendría de muy antiguo según se deduce de esta cita pues aun cuando su realización se constata a principios del siglo $\mathrm{XVI}^{3}$, es más que probable que ya existiera con anterioridad. La ciudad es la encargada de organizar tal evento con motivo de las fiestas patronales ${ }^{4}$. El lugar elegido es la plaza del Hospital Real por ser la más apropiada no sólo por sus mayores dimensiones sino por estar rodeada por casi todos los edificios representativos, como son la Catedral, el Palacio Arzobispal, el Hospital Real y el Colegio de San Jerónimo, faltando tan sólo las Casas Consistoriales ubicadas en la Plaza del Campo. Además todos estos edificios disponen de balcones para que sus comunidades, familiares, criados y amigos - -el Colegio de San Jerónimo acogía a la Universidad de Fonseca - puedan ver el espectáculo. Sin embargo, la ciudad y la comunidad del Colegio de San Clemente, al no contar con tal privilegio, encargaban la construcción de tablados. La ciudad se ocupaba de la eventual construcción de una plaza de toros, compuesta por un cierre de

${ }^{2}$ Archivo Histórico Universitario de Santiago, Fondo del Ayuntamiento, Libros de Consistorios, Agosto-Diciembre 1754, fol. 251. Esta cita también aparece recogida por PÉREZ COSTANTI, P., "Las corridas de toros en Santiago", en Notas Viejas Galicianas, T. II, Vigo 1925, págs. 231-247.

${ }^{3}$ En los años de 1532 y 1533 se realizaron corridas de toros en la Plaza del Hospital. Cf. BARREIRO, B., "Las fiestas compostelanas del mes de Julio por el Apóstol Santiago desde el siglo décimo sexto", Galicia Diplomática, T. I, 1882, pág. 22

${ }^{4}$ Las dificultades económicas, por las que algunas veces pasaba el tesoro municipal, afectaban directamente a estas fiestas. Para solventar estas situaciones el Conde de Altamira, D. Rodrigo de Moscoso «estableció la cofradia del Sr. Santiago dándole constituciones y declarándose en ellas por patrono con la carga de contribuir a la mayor solemnidad del dia 25 de julior. A la iniciativa de este Conde también se debe la introducción y costumbre de los juegos de cañas en las fiestas del Apóstol. Para su realización se levantaba un palenque con barreras y tablados en la Plaza del Hospital. Cf. BARREIRO, B., Ibidem, págs. 55-56.

"CUADERNOS DE ESTUdIOS GALLEGOS", Tomo XLII, Fascículo 107, Santiago 1995. 
madera con tablados o talanqueras desde donde veía la corrida ${ }^{5}$. La obra se sacaba a pregón y la realizaba el mejor postor, que se veía obligado a buscar las tablas, pontones y maderas suficientes. El día señalado era el 24 de julio, víspera de la solemnidad del Apóstol. Otros motivos que justifican la realización de corridas eran las visitas de los Reyes ${ }^{6}$, las celebraciones excepcionales y fiestas particulares que solían tener lugar en distintos espacios o plazas de la ciudad: Puerta del Camino, Plaza del Campo ${ }^{7}$, Plaza de la Azabachería ${ }^{8}$ y Plaza del Hospital Real ${ }^{9}$.

¿Qué ocurrió el Año Santo de 1745? El 12 de julio D. Alonso de Lago Basarte y Navia, como alcalde, mandó publicar el bando para el remate del cerramiento de tablados y talanqueras de la plaza del Obradoiro. Cinco días después se aceptó la postura de Domingo Lorenzo, maestro de carpintería, por 110 reales de vellón y «quedandole a su arvitrio el estipendio que le pague el Colegio de San Clemente, y lo que ha de usufructuar de particulares que concurran a ver la función». Lo ejecutaría en el sitio acostumbrado, delante de las columnas y cadenas del Hospital, con una separación de dos varas. El día 22, estando cerrada la plaza y hechas

\footnotetext{
${ }^{5}$ Durante el siglo XVII, los «tratos» y gremios (zapatería, cera, joyería, paños, vino, grosura...) de la ciudad tenían la obligación de contribuir, con ciertas cantidades de dinero, a los gastos que ocasionaba la construcción de tablados en la plaza del Hospital Real. Cf. PÉREZ COSTANTI, P., Art. cit.

${ }^{6}$ En la visita que realiza a Santiago la Reina D. Mariana de Newbourg y el Príncipe D. Luis, Gran Maestre de la Orden Teutónica, ocurrida en abril de 1690, se dispuso la realización de fuegos y la fabricación de un tablado en la «plaza del Campo frente a las Casas de Ayuntamiento», pero enterados que se aposentaría en el Palacio Arzobispal decidieron trasladar el tablado a la del Hospital Real «frente a los balcones de dho palacio, muy suntuoso con sus corredores, como se hizo de tres altos... con la Ystoria y representacion de hiercoles para los fuegos». Se realizó la «fabrica de dicho castillo y tablado en tan breve tiempo ricamente pintado y dispuesto y en él trece figuras diferentes de hombres, mujeres, serpientes, leones, bueis y otras todas pintas y colmadas de diferentes fuegos»). Cf. "Venida de la Reina Ntra. Sra. Da Mariana de Newbourg y Serenisimo Principe D. Luis, Gran Maestre de la Orden Teutónica,...", Galicia Diplomática, T. I, 1882, pág. 7

${ }^{7}$ PÉREZ COSTANTI, P., Art. cit.

${ }^{8}$ LÓPEZ, R.J.: "Celebraciones públicas en Galicia durante el siglo XVIII" en Obradoiro de Historia Moderna, Universidad de Santiago 1990, págs. 189-190.

${ }^{9}$ Durante la visita que hizo Felipe II a Santiago, el 22 de junio de 1554, se celebraron grandes fiestas y el día de San Juan, el Rey, presenció la corrida de toros, que tuvo lugar en el Obradoiro, desde el Hospital Real. Cf. LÓPEZ FERREIRO, A., Historia de la S.A.M. Iglesia de Santiago, T. VIII, Santiago 1905, pág. 161.
}

"CUADERNOS DE ESTUdiOS GALlEGOS", Tomo XLII, Fascículo 107, Santiago 1995. 
las talanqueras, el administrador pidió a Domingo Lorenzo y otros oficiales que deshicieran una porción del tablado ${ }^{10}$. Ante la negativa de éstos, amparados en no haber introducido novedad respecto de otros años, el carpintero del Hospital, José de Rivas, y otros derribaron parte del tablado y amenazaron a los asentistas. Inmediatamente el alcalde trata de averiguar las causas de tal derribo, al mismo tiempo que dispone se vuelva a levantar el tablado deshecho bajo vigilancia militar. Estos pormenores no impidieron las fiestas taurinas de este año, pero generaron una importante polémica que fue, finalmente, remitida al Supremo Consejo para que emitiera su dictamen. Las posturas contrapuestas de las partes dan lugar a distintos informes que se envían a Madrid expresando los fundamentos de sus actuaciones.

Los motivos aducidos por el administrador, D. Manuel Noriega y Mier, eran la posesión de una parte de aquellas talanqueras; la altura del palco, que impedía la visión desde los balcones; y la necesidad de una puerta de comunicación entre la plaza y el hospital que debía estar abierta para el tránsito de peregrinos y otras personas hasta el comienzo de los festejos.

La respuesta de la ciudad no se deja esperar, exponiendo que tales reivindicaciones carecían de fundamento, ya que no tenía posesión en el tablado, pero si prefería este sitio al de los balcones de su fachada, el ayuntamiento no tendría ningún problema siempre que cumpliese tres condiciones, a saber: «que a der ser sin perjuicio de los tablados que ocupare la Ciudad, para si y para los Cavalleros de el Lugar, y forasteros que combida»; que este lugar lo ha de ocupar la comunidad del Hospital pero no sus criados, cocineros y sirvientes; y que ha de pagar su sitio como lo hacían los demás. Respecto a la puerta, sostiene su existencia y apertura desde siempre ${ }^{11}$. Además, la razón de esta pretendida posesión se reduce a «que algunas veces el Asentista de los Tablados de la ciudad, por faltarle maderas para ellos, las pedía prestadas al Carpintero del Real Hospital, y ese se las dava, con la condición de que le dexase una porcioncita de Tablado para veneficiarses, un beneficio que consistía en la venta de esas localidades a los mejores compradores. Como este año no hubo tal préstamo, el carpintero se veía privado de sus intereses y de aquí surgían las reivindicaciones de posesión por parte del administrador de la real institufol. 240 .

${ }^{10}$ A.H.U.S., Fondo del Ayuntamiento. Libros de Consistorios, $2^{\circ}$ Cuatrimestre 1745 ,

$"$ A.H.U.S., Ibidem, fols. 245-246.

"CUAdernos DE ESTUdios Gallegos", Tomo XLII, Fascículo 107, Santiago 1995. 
ción. Como complemento y apoyo, la ciudad aporta el testimonio de distintas personas sobre los actos. Uno de ellos es el de Domingo Lorenzo, maestro carpintero en quien ha recaído este año el remate. En su declaración manifiesta que la ciudad construye su talanquera por no poseer balcón en esta plaza, al igual que el Colegio de San Clemente, que la dispone a continuación, y «en el resto de este tablado y en el que se sigue que esta frontero a la Iglesia, se sientan pocas personas por no haber mucho espacio. El castillo de fuegos que hace el Cabildo ocupa la mayor parte de aquella azera». Otros testigos son Tiburzio de Roma ${ }^{12}$, Gregorio Rey ${ }^{13}, \mathrm{y}$ Pascual Martínez ${ }^{14}$.

Una vez que el Consejo ha examinado la documentación remitida, el Rey expide, el 10 de octubre de 1745, una Real Cédula exponiendo que la ciudad no podía fabricar los andamios en toda «la testera» del Hospital porque perjudicaba la visión desde los balcones, impedía el libre acceso y le daba la espalda. El infringimiento conllevaría una multa de 4.000 duca$\operatorname{dos}^{15}$.

\footnotetext{
${ }^{12}$ «carpintero y vecino de la ciudad que afirma conocer bien ello por haber trabajado en diferentes años como oficial de Domingo Lorenzo, Pedro Rosende, y otros».

${ }_{13}$ «Carpintero... y siendo carpintero aparejador numerario de dho Hospital a tomado a su cargo diferentes años el cerrado de dha plaza, y fabrica de talanqueras, y las ha formado en la manera que queda dicho, sin que hiciese, ni tubiese orden de dho Administrador de hacer tablado alguno para el, y familia del Hospital, solo si que siendo Beedor de aquella Real Casa D. Juan Crespo, aora difunto por este se le encargo particularmente algunos años, le hiciese tablado frente a dha Puerta del Hospital, para en el ver la fiesta de familia de una Hermana suia y otros sus amigos que tenia en esta ciudad, lo que ha executado el que declara, y por que le pagó su alquiler como qualquier particular de la Ciudad sin que fuese esto encargo de dho Hospital».

${ }^{14}$ Carpintero y testigo que ha realizado, en diferentes años, la construcción de los de la ciudad.

${ }^{15}$ Esta Real Cédula va dirigida a D. Pedro de Saura Valcarcel, Oidor de la Real Audiencia de La Coruña; «... por la qual os mando, que luego que la recibais, habais notificar a la Ciudad, que en adelante no mande, ni permita fabricar Andamios alguno en las fiestás de Toros que hiciere en la Plaza donde esta situado el Real Hospital en toda la testera de la expresada Real Casa y Hospital, por el qual se impida la vista y uso libre de sus Balcones, Ventanas, entradas, y salidas, ni se continue la Yndecencia de dejarsela a las espaldas deviendo quedar por la authoridad de una Casa Real tan distinguida enteramente despejada, libre y desembarazada como si efectivamente la havitase mi Real Persona, estando destinado a este fin los quatro Balcones que corresponden a ella, segun y como se practica, en mi corte y los demas Palacios de España; y que la Ciudad lo cumpla vajo la pena de quatro mil ducados, que se sacaran a sus Capitulares de vienes propios si
}

"CUADERNOS DE ESTUDIOS GALLEGOS", Tomo XLII, Fascículo 107, Santiago 1995. 
El Ayuntamiento, no convencido por las disposiciones reales, envió nueva petición al monarca. El Delegado en Madrid, D. Francisco Xavier Fernández Busto, pide, el 23 de marzo de 1746, le remitan todos los documentos acreditativos y justificativos de la pretensión, tanto en lo concerniente a la situación del terreno en que se arma el tablado y su posesión, como a la ausencia de otro lugar para colocar el tablado. Al mismo tiempo que se garantiza la no pertenencia ni perjuicio del Hospital ${ }^{16}$.

Un acontecimiento inesperado se produce este año, la muerte de Felipe V. Semejante noticia es motivo suficiente para que la ciudad suprima la corrida de toros como ya había ocurrido anteriormente cuando murió, en 1689 , la reina Isabel de Orleans, primera mujer de Carlos II ${ }^{17}$.

El 4 de febrero de 1747, ante la ausencia de la resolución del Consejo, la ciudad solicita permiso para construir los andamios y tablados en la forma y lugar acostumbrados, «como se habia hecho en 1745». Su solicitud está fundamentada en «la incomodidad con que veya las fiestas en la Zera del Sol, siendo regular apetecer la sombra en una estazion tan rigurosa como la del estion. La Cámara comisiona al Arzobispo para que escuche las razones de las partes y consiga un acuerdo. El 10 de mayo se informó al administrador de los documentos y plano que la ciudad ha remitido a Madrid. Evidentemente no debieron ser bien recibidas estas noticias ya que, inmediatamente, presentó las declaraciones de distintos carpinteros que confirmaban sus criterios ${ }^{18}$. Buena muestra de ellas es la de

\footnotetext{
le fabricare, dejando copia en sus Libros de esta mi Real Cedula para su observancia, y que luego, que la Ciudad sea requerida remita Testimonio a la letra a manos de mi infrascripto Secretario del Acuerdo celebrado en su Ayuntamiento, en el qual se deliberó formar el nuebo Andamio impartiendo para ello el auxilio militar, como tambien de todos los mas celebrados con el motibo de la fiesta de Toros, de este presente año de la fecha, con expresion de los Alcaldes y Capitulares que concurrieron, y asimismo fee de no haber quedado otros algunos. Todo lo qual es mi voluntad cometeros a vos el referido D. Pedro Saura Valcalzel, para que como os lo mando, lo hagais cumplir y ejecutar sin escusa ni dilación alguna, que asi procede de mi Real voluntad. Fecha en San Yldefonso a diez de Octubre de mil Setecientos quarenta y cinco».

${ }^{16}$ A.H.U.S., Idibem, Enero-Abril 1746, pág. 306.

${ }^{17}$ A.H.U.S., Ibidem, Mayo-Julio 1746, pág. 308.

${ }^{18}$ Otros testigos son: Joseph Antonio de Neyra, carpintero, vezino de la parroquia de Santa Susana. Pedro García, carpintero, vezino de la parroquia de San Fructuoso de dentro.
}

"CUADERNOS DE ESTUdiOS GALlEGOS", Tomo XLII, Fascículo 107, Santiago 1995. 
Domingo de San Martín ${ }^{19}$, quien en su disertación sobre el asentamiento del tablado en la plaza expone que en un principio se colocaba en el espacio existente entre el "castillo de fuego" y uno de los postes del patio del Hospital, haciendo frente al Palacio Arzobispal e Iglesia y que después, hacia 1712 fue trasladado a la fachada del Hospital, delante de sus cadenas $^{20}$. Otros trestimonios son los de Joseph Bauptista ${ }^{21}$, que señala la posesión que tenía el Hospital para levantar un tablado en frente de su puerta principal, y Joseph Antonio Picon ${ }^{22}$.

El 30 de mayo, el Arzobispo emite su juicio asegurando que la antigüedad del derecho de la ciudad sobre el sitio es de treinta y tantos años y se debe a la influencia del regidor D. Andrés Carvajal en el administrador

${ }^{19}$ Domingo de San Martín, carpintero, vecino de la parroquia de Santa Susana de afuera extramuros, dijo «que se acuerda por haverlo visto, sin que haga memoria del año fixo, solo si, que le parece habrá unos treinta y tantos, que la Ciudad de Santiago empezó a poner tablado para ver la corrida de toros vispera del Señor Santiago Apostol Patron de España, delante de las Cadenas, y principal fachada de este Real Hospital, porque antes, desde el tiempo de su acordanza, y segun lo que siempre ha oido, le ponia, y ha puesto en el sitio que media entre el Castillo de fuego que se construye todos los años en la plaza del Hospital, y el poste que corresponde al enlosado de él, y haze frente a la santa Yglesia, y al Palacio Arzobispal, cerrandose con tablas toda la tirantez, o testera de este Real Hospital, sobre las que no se ponia ningun tablado; y tambien se acuerda de que el primero que ha puesto el tablado de orden de la Ciudad, haciendo espaldas al Hospital, se llamaba Joseph de Seixas conocido por chancas = Que asimismo sabe como hecho notorio, que en toda la testera del Colegio de San Geronimo, que haze frente a la de esta Real Casa, y cierra por aquella parte la referida Plaza, no se ponen Tablados algunos de orden de la ciudad, y solo lo hazen los Carpinteros del Colegio de orden de sus Superiores vajo de los Balcones de el, y lo mismo sucede devajo de los de el venerable Dean y Cavildo, y Palacio Arzobispal, sin que sepa el testigo, que la Ciudad tenga mas accion, que en la fabrica de el Toril, que se forma a un Rincon del referido Palacio a la salida de la Plaza...».

${ }^{20}$ Joseph de Seixas, conocido por chancas, fue el maestro carpintero que realizó dicho traslado. Para conocer algo más sobre este carpintero se puede consultar el artículo de TAÍN GUZMÁN, M., "El taller y la biblioteca del Maestro de obras compostelano José de Seixas", en Cuadernos de Estudios Gallegos, Santiago, 1993-1994, págs. 263-276.

${ }^{21}$ Carpintero y vezino de la parroquia de San Andrés.

${ }^{22}$ Maestro Carpintero, vezino de la parroquia de Santa Maria de Sar extramuros, y de «hedad cincuenta y seis años poco mas o menos, $y$ de acordanza cuarenta, dice que save $y$ le consta por haverlo visto, que para la corrida de Toros que se haze en la Plaza del Hospital, no se cerraba esta, como ahora se haze, y que solo se cerraba a avierto de las dos Calles de Palacio y San Francisco, quedando libre y comunicable con la Plaza el empedrado y cadenas inmediato a ella, sin que delante del Real Hospital se formase Tablado ni andamio alguno... hasta que despues habria como treinta años poco mas o menos... la ciudad mudo su Tabladon.

"CUADERNOS DE ESTUDIOS GALLEGOS", Tomo XLII, Fascículo 107, Santiago 1995. 
D. Francisco Ignacio de Aranciaga. Este informe no debió ser el único o determinante, ya que el 12 de julio se recibió una nueva real orden del Supremo Consejo por la cual se resolvía «por aora, y sin perxuicio del Real Hospital, ni que sirva de exemplar para lo subcesibo en el ynterin, que el señor Arzobispo ebaqua este encargo; ponga la Ciudad el andamio en la conformidad que antes lo executaba, dexando enteramente libre la entrada del Real Hospital, sin elebar el Tablado de suerte que embarace la vista de los Balcones, antes se le dexe libre y desembarazada». La ciudad afirma que no habrá ningún exceso y dejará libre la entrada «por tres puertas que tiene Calles y transitos mui amplios, por donde no solo transitan gentes, sino también carros y cavallerizas», y sin estorbar la visión de los balcones. La razón fundamental por la que se ha dado esta autorización está reflejada en la declaración del fiscal y no es otra que la situación del palco en la «Azera del Sol» no era el lugar más adecuado para que el Consistorio presenciara la fiesta, considerándola causa suficiente para cambiar su ubicación. Además, la ciudad como organizadora y cuerpo que preside este acto merecía alguna consideración acorde a su rango pero, eso sí, sin «alegar derecho y disponer a su arbitrio de la fachada del Hospital» y solicitando siempre un lugar en su delantera que deje libre la vista desde los balcones.

Una vez conseguido el permiso para el palco municipal, el alcalde, D. Francisco Javier García Navarrete, ordena la publicación del bando para el cierre con tablados de la Plaza del Obradoiro. Su remate recayó en Francisco Rodríguez, maestro de carpintería, en la cantidad de 166 reales y bajo ciertas condiciones ${ }^{23}$. Este operario junto a Pedro y Joseph de Trasmonte, también maestros carpinteros, fueron requeridos, el 25 de julio, para contestar varias preguntas. Ellos hicieron los cerrados, talanqueras y asientos conforme a las condiciones del remate. La separación de tres varas de las columnas del Hospital era suficiente para el paso de los carros como quedó demostrado con uno de leña y dos de enfermos. La puerta portátil del tablado, desviada a la misma distancia, tenía tanto de altura como de anchura, 10 cuartas, y por ella entraron carros de bueyes «cargados con piedra de Canteria para la obra de torres y espejo que se está haciendo en la Santa Yglesià. Además, los tablados, al no sobrepasar la altura de 4 varas, no suponían obstáculo para los balcones ni para aquellas personas que, subidas a las columnas, podian ver la plaza.

\footnotetext{
${ }^{23}$ Véase apéndice documental $n^{\circ} 1$
} 
Según Pérez Costanti en esta plaza se siguieron lidiando toros hasta 1802. Posteriormente este acto fue exclusivo de los Años Santos y se realizó en el campo de Santa Susana ${ }^{24}$.

Las fiestas del Santo Apóstol se celebraban durante dos días y a ellas acudía un ministro real, normalmente un oidor de la Real Audiencia de este Reino, que en nombre del monarca hace la ofrenda al Apóstol. En su víspera, por la tarde y durante dos horas, tenía lugar una corrida de toros en la plaza del Obradoiro. Pero ¿en qué consiste tal acto? Un testimonio emitido el 7 de septiembre de 1745, posiblemente subjetivo dado su tono sarcástico, lo desvela: «la fiesta de toros consiste en coger cuatro bueyes en el campo atarlos de pies y manos, y poner cada uno dentro de un carro, y tirando otros dos de el, los traen desde el Campo a la Plaza, donde los desatan, y meten a palos en el Toril. No hay hombre a caballo ni a pie que los sortee reduciéndose la funcion a ponerle a alguno una manta de fuego con coetes, $y$ hechando perros a otros, para que los maten. La Ciudad viene formada a pie a la plaza con un Clarin sin Trompeta que sepa tocar, y una Gaita gallega que le precede con su Tamborcillo, aunque desde que hay Milicias tambien trahe las Cajas, y el pifano de estas, de cuia fiesta los forasteros no solamente se rien, sino es que la admiran muchisimo por ridicula. Vea V.S. si una Ciudad que tanto bocea la estrella que la alumbra portandose en unas fiestas tan solemnes como el Sagrado Apostol Patron de España se trata con esta llaneza...».

\section{LA CONFIGURACIÓN URBANÍSTICA DE LA PLAZA}

La morfología de la ciudad es el resultado de constantes transformaciones ocurridas desde su nacimiento, en la Alta Edad Media, hasta la actualidad. Las fuertes pendientes del terreno, originadas por el asentamiento de la ciudad en un cerro elevado, serán un sello permanente, aun cuando se halla atentado contra él en algunos puntos significativos. La construcción de la Basílica había generado espacios a su alrededor que, en fechas no muy lejanas, fueron parcialmente invadidos por el caserío. A medida que pasan los años las transformaciones llevadas a cabo en la Iglesia van a tener una repercusión directa en el tejido urbano. La consti-

\footnotetext{
${ }^{24}$ PÉREZ COSTANTI, P., Art. cit.

"Cuadernos de eStudios GALlegoS", Tomo XLII, Fascículo 107, Santiago 1995.
} 
tución de éste viene dada más por una agregación espontánea que por un plan preestablecido. "En Compostela la arquitectura ha construido la ciudad, la ha estructurado monumentalmente y la ha codificado tipológicamente" ${ }^{125}$. Es un organismo vivo que, al mismo tiempo que sobrevive manteniendo sus orígenes, se adapta a los cambios exigidos por cada momento. Sus monumentos, casas, calles y plazas son documentos que nos permiten conocer la impronta dejada por épocas pasadas.

El elemento constitutivo del panorama urbano compostelano que nos interesa es la plaza del Obradoiro. Su historia refleja todas las características que definen una plaza como lugar espacioso y punto de encuentro de calles, apto para las relaciones humanas y donde se celebran mercados y fiestas. Si a esto añadimos que fue perfilada por los edificios representativos de los distintos poderes de la ciudad, no nos extraña que se convirtiera en centro neurálgico de la actividad ciudadana.

Su configuración urbanística está marcada por los edificios emblemáticos de la Catedral y el Palacio Arzobispal al Este, el Hospital Real al Norte, la fundación plurifuncional del Arzobispo Rajoy al Oeste y el Colegio de San Jerónimo al Sur, edificios que en los años 1745-1747, a excepción del de Rajoy, estaban ya construidos desde hacía tiempo y en ciertos casos habían experimentado, en mayor o menor medida, alguna transformación como podremos observar a continuación.

La importante actividad edilicia llevada a cabo a lo largo del siglo XVI en este espacio y la existencia de un plano de finales de siglo, nos permiten tomar esta época como punto de partida. En 1499 se emprende la fundación regia de un hospital con la intención de construirlo intramuros y en un lugar privilegiado. El espacio elegido, finalmente, fue en las cercanías de la fachada occidental de la Catedral, a pesar del inconveniente que suponía la compra y derribo de casas y huertas allí existentes para poder materializar el proyecto de Enrique Egas $^{26}$. Su construcción anuncia y determina la futura configuración de la plaza, al mismo tiempo que le da uno de los nombres por la que va a ser conocida: Plaza del Hospital Real.

${ }^{25}$ BONET CORREA, A., "La estructura urbana de Santiago de Compostela" en Proyecto y Ciudad histórica, C.O.A.G., Santiago 1976, pág. 32.

${ }^{25}$ AZCARATE, J.M. de, "La labor de Egas en el Hospital Real de Santiago de Compostela", en Homenaje al profesor Dr. D. Roggen. Bruselas, 1955; y "El Hospital Real de Santiago: La obra y los artistas", Compostellanum, 1965.

"CUADERNOS DE ESTUDIOS GALlEGOS", Tomo XLII, Fascículo 107, Santiago 1995. 
En el Palacio Arzobispal también se producen importantes reformas y nuevas obras, destacando las propuestas por el arzobispo Francisco Blanco en 1575 referentes a la «reedificación de la puerta que estaba en la esquina del Obradoiro y que salía a la Plaza del Hospital Real y la construcción de una torre en la misma acera» ${ }^{27}$.

Otra iniciativa eclesiástica, esta vez del Cabildo, puede considerarse también decisiva en la configuración de la plaza. El Cabildo con la colaboración del arzobispo Fonseca, toman la decisión de derribar el claustro viejo y erigir uno nuevo que, por su mayor amplitud, requiere la adquisición de las casas y calles vecinas para dar cabida al proyecto trazado por Juan de Alava. De esta construcción sólo nos interesa el lienzo occidental del claustro. En él se está trabajando en 1566, según se desprende del siguiente texto del acta capitular, del 26 de marzo: «Atenta la nescesidad que ay en la obra nueva que se aze en la plaça del ospital del quarto nuebo que es el estribo de la torre de las campanas y del lienço de la claustra questá á la parte de la travesia... se mando se prosiga la obra conforme a la traza que hizo Rodrigo Gil hasta llegar al cabo de la esquina, y que se compren las casas questán junto al lienço de la dicha claustra nescesarias para la dicha obra $\rangle^{28}$. Se ha señalado el año de 1590 como la data en que se terminó el claustro ${ }^{29}$.

En el plano de finales del siglo XVI esta plaza, denominada «Plaça del Hospital», aparece perfilada por «El grande Hospital Real», la «Huerta del Arzobispo», la calle de la Azabachería, las «Casas del Arçobispal», la Catedral, el Claustro, la calle del Franco, una manzana de casas o huertas, el paseo de ronda y la muralla con un torreón adosado, la llamada «Carcel», y la «Puerta de las huertas». Delante de la fachada del Hospital se constatan los límites de la lonja y una línea dividiendo parte de la plaza con la que seguramente se pretenda señalar la existencia de un muro. Su figura es irregular y de gran amplitud (Fig. 1).

En el siglo XVII estos edificios sufren reformas y añadidos. En 1611 Jácome Fernández el Viejo reforma la fachada del Palacio Arzobispal y, en 1614, conforme a su traza, Francisco González de Araujo añade la

${ }^{27}$ LÓPEZ FERREIRO, A., Op. cit., pág. 273.

${ }^{28}$ LÓPEZ FERREIRO, A., Op. cit., pág. 177.

${ }^{29}$ LÓPEZ FERREIRO, A., Op. cit., pág. 179; VILA JATO, Ma D., "El Claustro de la Catedral de Santiago", en Estudios de Historia del Arte en Honor del Prof. Dr. D. Ramón Otero Túnez, Universidad de Santiago de Compostela 1993, pág. 113.

"CUADERNOS DE ESTUDiOS GALLEGOS", Tomo XLII, Fascículo 107, Santiago 1995. 


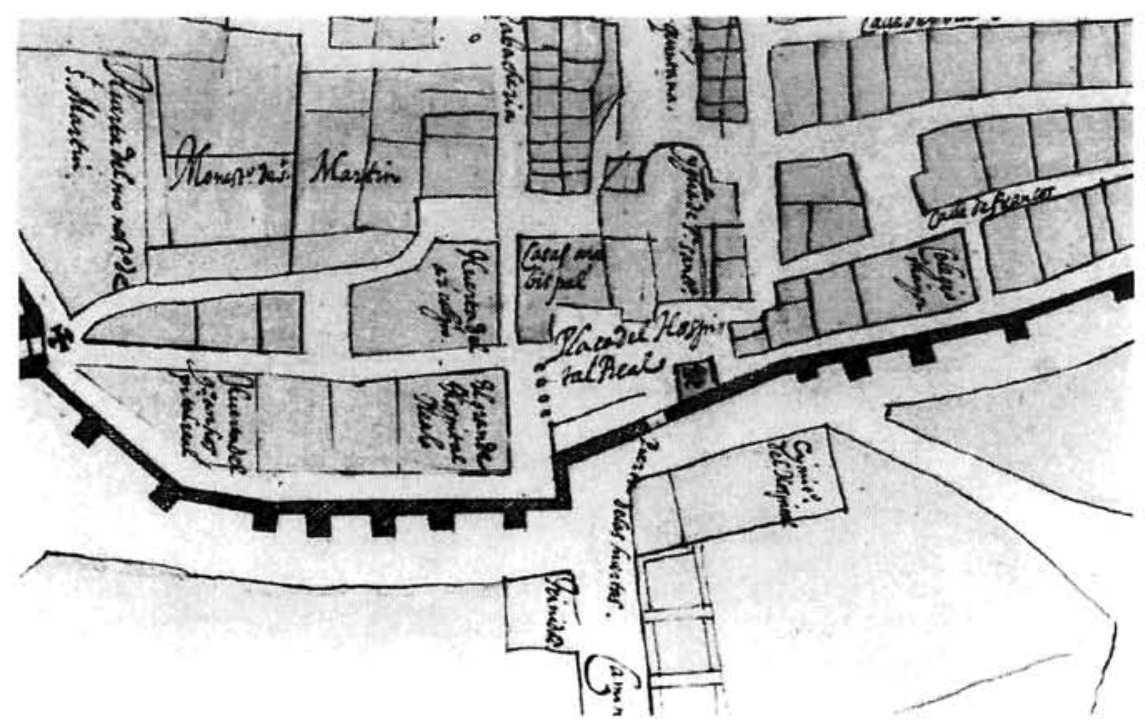

Figura 1. Anónimo. Plano de la ciudad de Santiago a finales del siglo XVI. Archivo General de Simancas.

galería abierta o "loggia" y la torre de la Vela que coronan el lienzo occidental del Claustro. La escalera que comunica la plaza con la entrada de la Catedral es el resultado de dos proyectos complementarios. Por una parte estaría la escalera exterior, construida entorno a 1520-1524, y por otra la escalera interna comenzada en 1606 conforme a la traza de Ginés Martínez de Aranda $^{30}$. En 1675, por un desplome en la fachada del Hospital Real, Fray Tomás Alonso es el encargado de su reconstrucción, introduciendo el balcón y tres ventanas decoradas con guirnaldas ${ }^{31}$. También se llevaron a cabo obras de nueva planta como es el Colegio de San Jerónimo (1651/ 1652), atribuido a José Peña de Toro, y la Cárcel Seglar.

${ }^{30}$ VILA JATO, M.D., Galicia en la época del Renacimiento, Santiago 1993, págs. 132 134; GOY DIZ, A., La arquitectura en Galicia en el paso del Renacimiento al Barroco, 1600-1650: Santiago y su área de influencia, Santiago 1994, T. I-2 ${ }^{\mathrm{a}}$ parte, págs. 1323-1332 (Tésis inédita).

${ }^{31}$ PÉREZ COSTANTI, P., "La reedificación de la fachada del Gran Hospital en 1678" en Notas Viejas Galicianas, Santiago 1993, págs. 413-414; BONET CORREA, A., La arquitectura en Galicia durante el siglo XVII, Madrid 1984, págs. 445-446.

"CUADERNOS DE ESTUDIOS GALLEGOS", Tomo XLII, Fascículo 107, Santiago 1995. 
Otra fuente de obligada consulta para nuestro estudio son las descripciones hechas por distintos personajes que han visto y conocido Compostela a lo largo de este siglo ${ }^{32}$. Nos interesan fundamentalmente aquellas que recogen aspectos concretos de esta plaza. Particularmente interesante es la visión que da Hernando Ojea de una ciudad de figura «oval, ochavada, y casi redonda), rodeada por una muralla con torres y con siete puertas y que al occidente, «sobre una gran barranca», se encuentra una «grande y hermosa plaça» delimitada al oriente por las Casas Arzobispales y Catedral, al norte por el Hospital y su lonja «de doze o catorce varas de ancho» con pilares encadenados, y al oeste por la muralla con un castillo o torre adosada y con la puerta de las Huertas ${ }^{33}$. También disponemos de otros documentos que reúnen al mismo tiempo la descripción y su plasmación gráfica. Claros ejemplos son los dibujos e informe que de la fachada occidental de la Catedral hace el canónigo Vega y Verdugo ${ }^{34}$ (Fig. 2) y la visita de Cosme de Médicis con sus respectivos comentarios de Lorenzo Magaloti y visión panorámica de la ciudad amurallada desde el Campo de Santa Susana del pintor Pier María Balbijis (Fig. 3).

${ }^{32}$ La imagen general dada por Jerónimo del Hoyo sigue siendo medieval, con gran hacinamiento de su caserío en el que predomina la madera, la estrechez y el mal estado e irregularidad de sus calles y callejuelas. Cf. HOYO, J. del, Memorias del Arzobispo de Santiago (1607), edic. preparada por Rodríguez González, A. y Varela Jácome, B., Santiago, págs. 42 y ss.

${ }^{33}$ OJEA, FR. HERNANDO (O.P.) 1543-1615, Historia del Glorioso Apostol Santiago. Introducción y cuidado de la edición facsímil por Ignacio Cabano Vázquez, Santiago 1993.

${ }^{34}$ «La de esta santa Yglesia es una de las mejores que tiene España, porque se compone, de un lado, del lienço de torres, puertas y ventanas, de los quartos de la fábrica y cabildo y, del otro, del altura del palaçio arçobispal, a que se le añaden a haçer labor el Hospital y Colegio nuevo. En medio de este adorno y aparato está una escalera tan rara en su disposiçión y arquitectura que no hay quien no admire su hermosura, los parapetos, bellotas y estatuas toscanas son muy buenas; las pilastras, balcones de piedra y remates de los dos estribos nuevos». Cf. VEGA y VERDUGO, J. de, "Memorias sobre obras en la Catedral de Santiago (1657-1666)" en Opúsculos gallegos sobre las Bellas Artes de los siglos XVII y XVIII edic. al cuidado de Sánchez Cantón, F.J. Santiago 1956, pág. 47.

${ }^{35}$ «La Cittá di S. Jago é posta nell'alto,... Piccola, brutta, e per lo piú fabbricata di legno; le mura sono di pietra tramezzate da torri, ma tutte ricoperte d'ellera, e gran parte di esse in stato di rovinare... A questa che é la piú riguradevole stá davanti una piazza, che termina con le mura, de ha le sue tre facce occupate una dalla Chiesa, che

"CUADERNOS DE ESTUDIOS GALLEGOS", Tomo XLII, Fascículo 107, Santiago 1995 

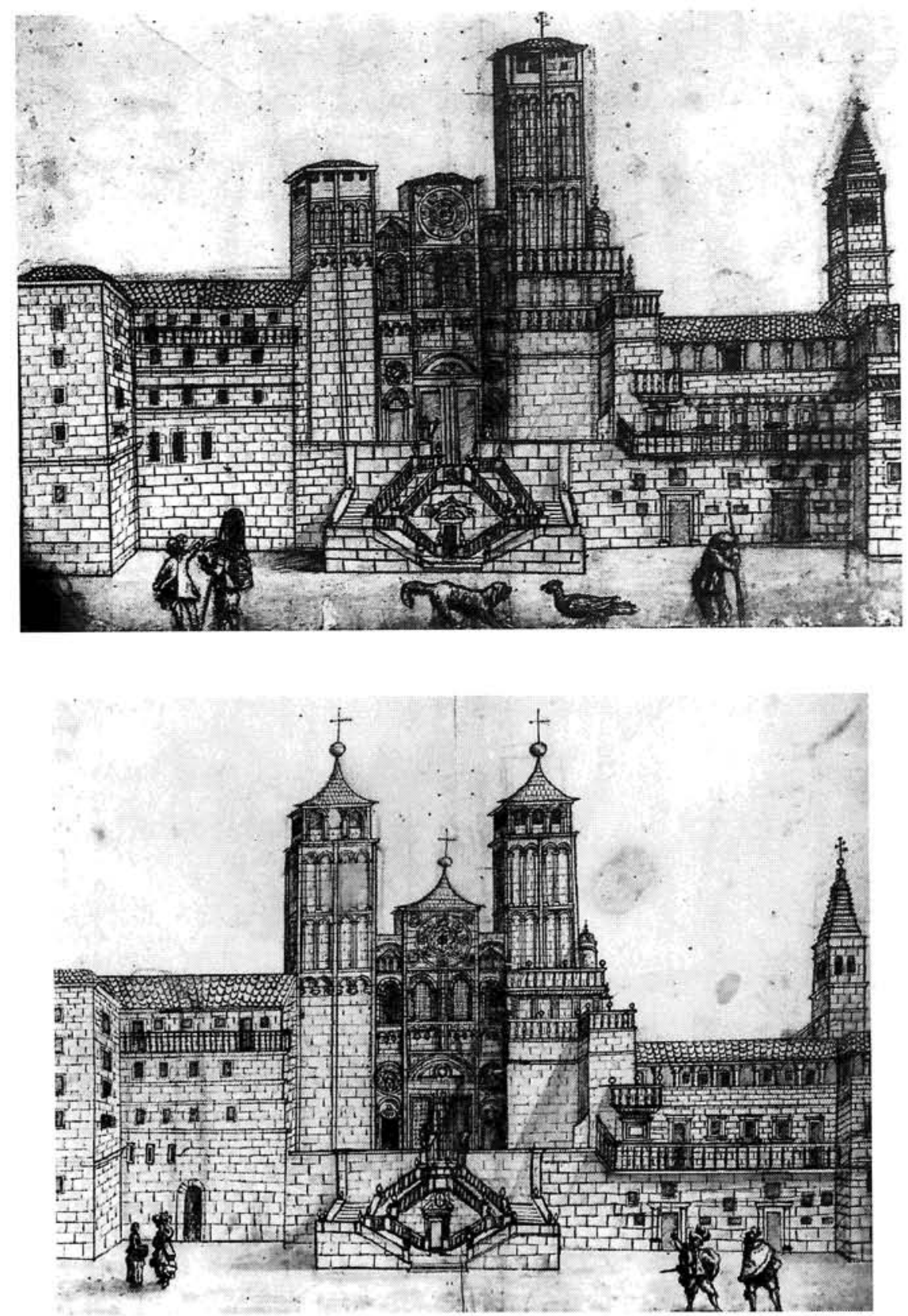

Figura 2. José Vega y Verdugo. Dibujos de la fachada oriental de la plaza del Obradoiro en "Memorias"... (1657-1666). Archivo de la Catedral de Santiago.

"CUADERNOS DE ESTUdIOS GALLEGOS", Tomo XLII, Fasciculo 107, Santiago 1995. 


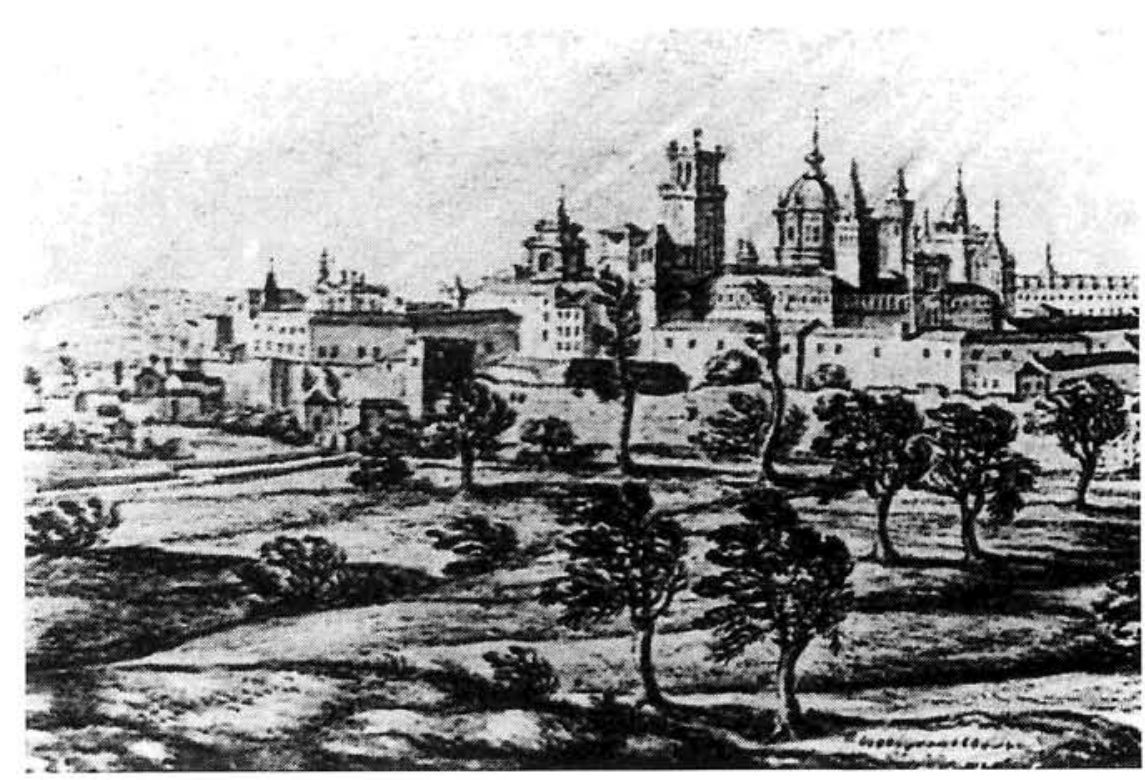

Figura 3. Pier María Balbi. Visión panorámica de Santiago en "Viaje de Cosme de Médicis..." (1668-1669). Biblioteca Xeral da Universidade de Santiago.

Las modificaciones sufridas por este ámbito hasta mediados del siglo XVIII se pueden observar en un plano anónimo, presumiblemente realizado en la década de los cincuenta y que se encuentra en el Instituto Padre Sarmiento (Fig. 4). Entre las novedades destaca el Colegio de San Jerónimo y la hilera de casas que definen el lienzo sur de la plaza; a continuación está la muralla con distintos edificios adosados y con sus dos puertas, la de las Huertas y la denominada "Falsa".

Este largo proceso de mutación toca a su fin con la construcción del Seminario de Rajoy cuyos preliminares conocemos sólo en parte gracias a unos planos de Miguel Ferro Caaveyro que fueron estudiados por Bonet Correa $^{36}$. Nuestra intención no es profundizar en su estudio sino recoger

resta inmezzo alla Canonica de al Palazzo Archiepiscopale, l'altra dalla Spedale de'Pellegrini, e l'altra da un Collegio; che tutte son fabbriche antiche, e magnifiche. Quest'ultimo é fondazione d'un Arcivescovo Fonseca». Cf. "Viaje de Cosme de Médicis por España y Portugal (1668-1669)", edic. preparada por Sánchez Rivera, A y Mariutti de Sánchez Rivero, A., págs. 333-334.

${ }^{36}$ BONET CORREA, A., "El urbanismo barroco y la plaza del Obradoiro en Santiago de Compostela", en Morfologia y ciudad, Barcelona, 1978, págs. 92-101.

"CUADERNOS DE ESTUdiOS GALlEGOS", Tomo XLII, Fasciculo I07, Santiago 1995. 


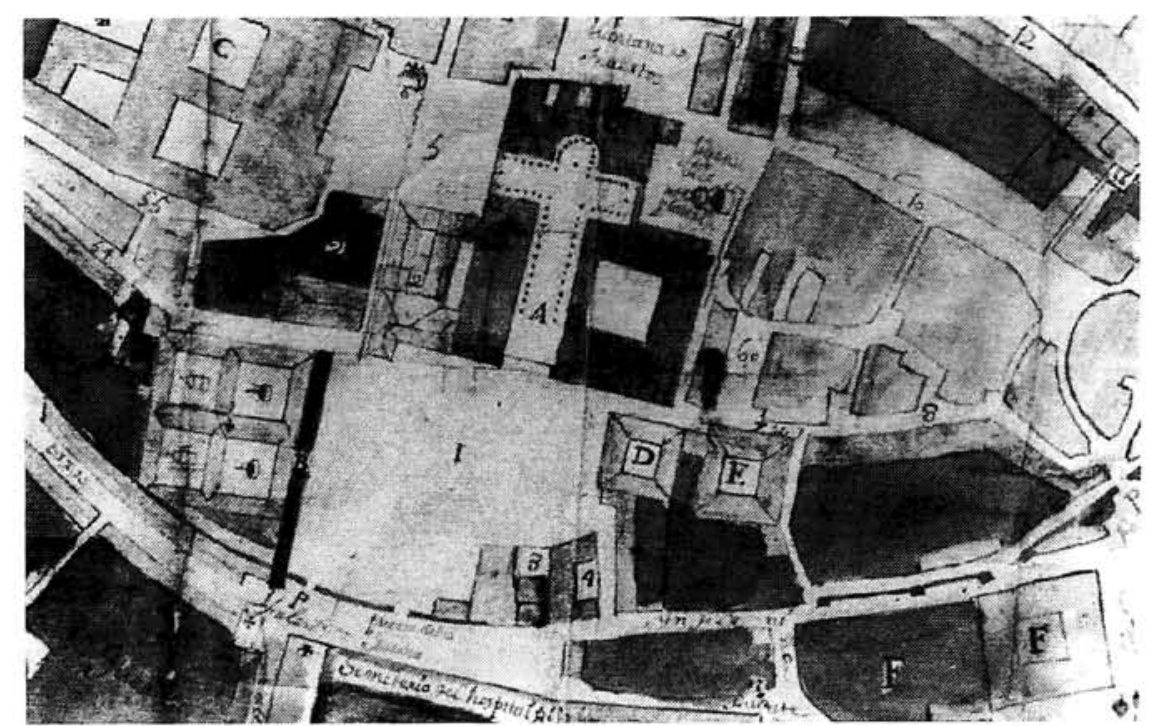

Figura 4. Anónimo. Plano de la ciudad de Santiago a mediados del siglo XVIII. Instituto Padre Sarmiento.

aquellos datos mostrados en el plano de la plaza que sean útiles para una mejor comprensión de nuestro trabajo (Fig. 5)

Esta rica documentación, gráfica y escrita, es el complemento ideal para la interpretación de un plano inédito que se conserva en los fondos del Archivo Histórico Nacional y que damos ahora a conocer por vez prime$\mathrm{ra}^{37}$. A través de él analizaremos y conoceremos el estado físico de la Plaza del Obradoiro y su revestimiento festivo en 1745, año Jubilar (Fig. 6).

El plano, de considerables dimensiones, esta trazado en papel muy fino. En su confección se han empleado distintas tintas, negra y roja, sombras, letras y "leyendas", buscando la mayor claridad expositiva. La obra expuesta es la plaza del Obradoiro con todos los edificios que la circunvalan y habitan. La ausencia de datación cronológica no presenta ningún obstáculo porque en el mismo legajo se encuentra una detallada explicación de la

${ }^{37}$ A.H.N. Consejos. Mapas y Planos no 1095.

"CUADERNOS DE ESTUdiOS GALlEGOS", Tomo XLII, Fascículo 107, Santiago 1995. 


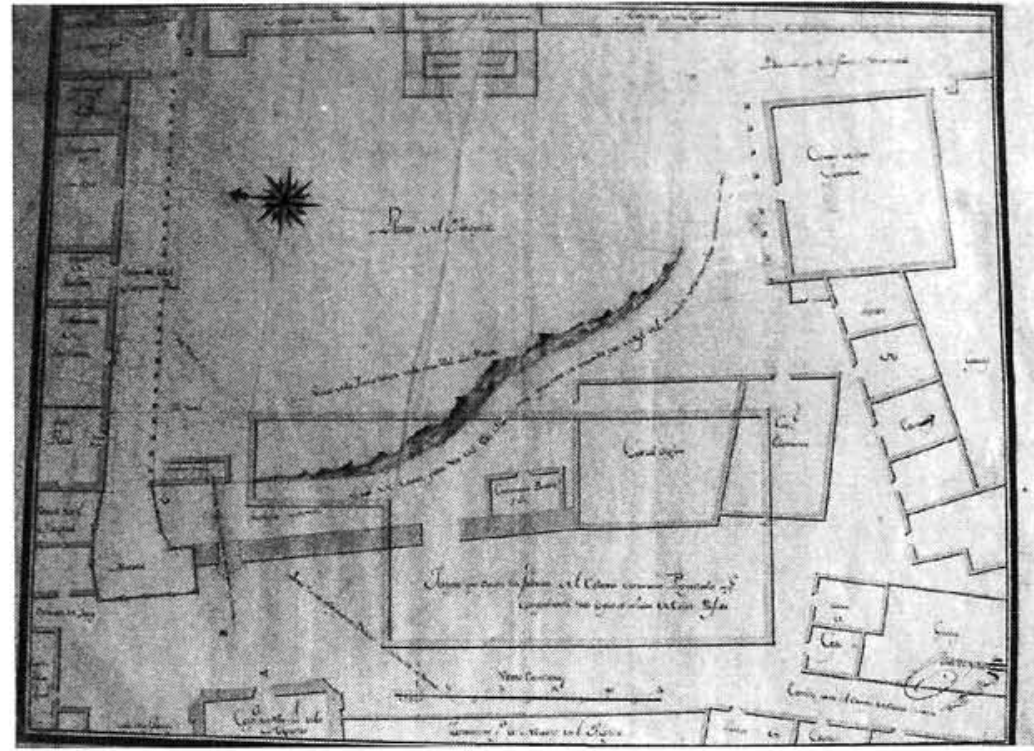

Figura 5. Miguel Ferro Caaveyro. Plano de la plaza del Obradoiro. $176 ?$. Archivo Histórico Nacional.

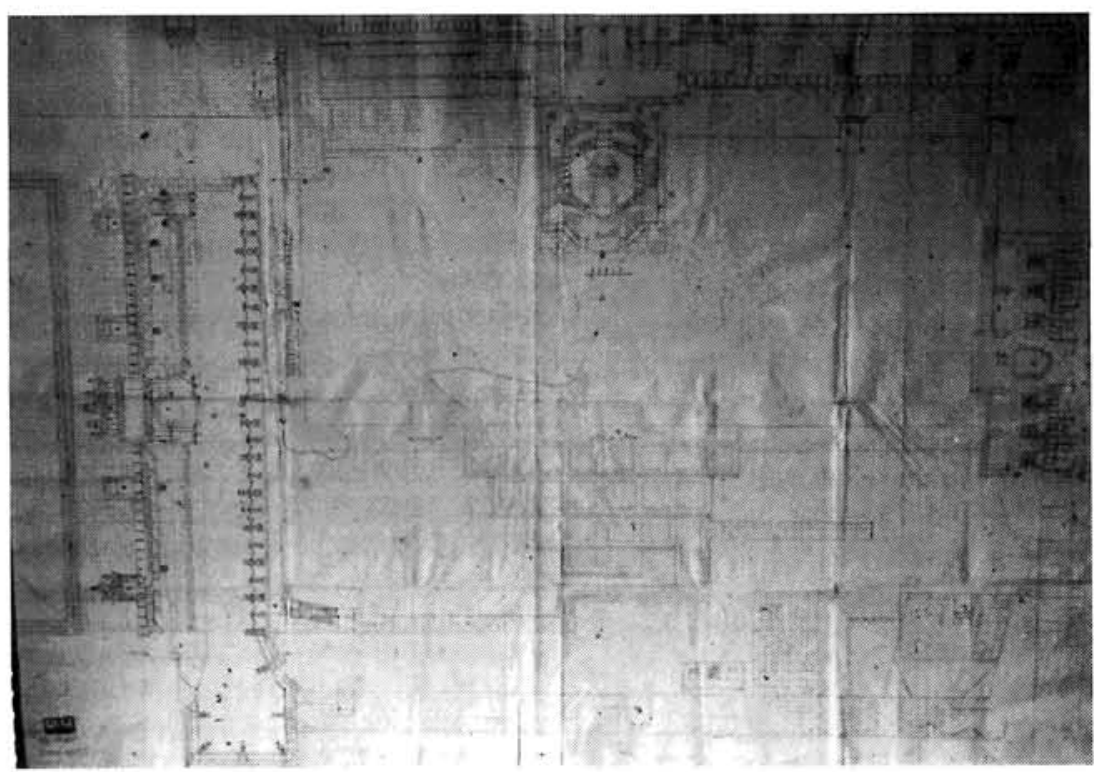

Figura 6. Francisco das Moas. Plano de la plaza del Obradoiro. 1745. Archivo Histórico Nacional.

"CUADERNOS DE ESTUDIOS GALLEGOS", Tomo XLII, Fascículo 107, Santiago 1995. 
plaza fechada el 17 de noviembre de $1745^{38}$ que, dada su estrecha relación con el plano tanto en grafía como en descripción, nos permite datarlo sin problemas en torno a estas fechas. Mayor dificultad presenta la ausencia de firma tanto en el plano como en la explicación. La consulta de los Libros de Consistorios de estos años, labor imprescindible en la búsqueda de datos que clarificaran su autoría, nos dio a conocer no uno sino dos nombres en relación con la realización de planos, a saber, Francisco das Moas, «maestro de escultor, y Arquitectura $\rangle^{39}$ y Miguel Antonio García y Bouzas de Castro, «Pinzelista $\rangle^{40}$. El análisis de los hechos ocurridos permitirá dilucidar que fue lo que realizó cada artista y con ello concluir la autoría del plano e informe. El motivo de su realización está en la controversia, anteriormente analizada, entre el Hospital y la ciudad. El 23 de marzo de 1746, Francisco Javier Fernández Busto, agente en Madrid, solicita todos los documentos acreditativos de la postura de la ciudad. En el Consistorio de 1 de abril, D. Andrés Mosquera presentó no sólo un "mapa" y su explicación firmada por Francisco das Moas, sino también una copia de los mismos. Al mismo tiempo se pasó revista a un memorial del autor mencionado en el que exponía se le había hecho el encargo de un «Mapa de la Plaza del Obradoiro, donde esta la Puerta principal de la Santa Yglesia de Sr. Santiago» para cuya realización había sido necesario tomar sus medidas. Además había elaborado, en otro papel, la explicación de su contenido y, últimamente, había sacado una copia del mapa. Una vez visto todo acuerdan

\footnotetext{
${ }^{38}$ «Descripcion de las medidas que he tomado de la plaza del obradoyro çita en esta ciudad de Santiago con sus entradas y salidas que esta ynclusa entre la Iglesia Catedral de Santiago Palacio Arzobispal, Ospital Real, Colegio de San Geronimo y Muralla que debide la Calle de las Guertas...». Por su importancia para la comprensión del plano de estudio hemos considerado oportuno reproducirlo integramente al final del trabajo. Véase apéndice documental $\mathrm{n}^{\circ} 2$.

${ }^{39}$ COUSELO BOUZAS, J., Galicia Artística en el siglo XVIII y primer tercio del XIX, Santiago 1932, págs. 457-459. Es escultor de Santiago y entre sus obras señala los siguientes retablos: el de la capilla mayor y la custodia de San Félix, el de la Azucena de la Catedral, el mayor de la iglesia de las Huerfanas, dos colaterales y el expositor para la Colegiata del Sar... No se constata ninguna obra de arquitectura.

${ }^{40}$ COUSELo BOUZAS, J., Op. cit., págs. 381-383. Es pintor, oriundo de Santiago, hijo de Juan Antonio García de Bouzas, pintor, y de Da Andrea de Castro y Calo, bautizado en Diciembre de 1697. Su oficio lo aprendería de la mano de su padre a pie de obra. En colaboración realizó el dorado y pintura del retablo mayor y dos colaterales del Colegio de los jesuitas de Pontevedra. Una vez independizado trabaja en la Catedral de Lugo y en Betanzos.
}

"CUADERNOS DE ESTUdIOS GALlEGOS", Tomo XLII, Fascículo 107, Santiago 1995. 
pagarle no los 600 reales de vellón que pretendía sino tan sólo 360 y enviar a Madrid el Mapa y su explicación.

Teniendo en cuenta, por una parte, el encargo hecho a Francisco das Moas, y por otra, que el plano y la explicación de la plaza del Obradoiro se hacen de acuerdo con una pormenorizada labor de medición como nos anuncia el propio título de la misma «Descripción de las medidas que he tomado de la plaza del obradoyron; la fecha de su redacción y el que se trate de un documento separado, podemos concluir que la autoría del pliego explicativo y su plano recaería en el citado maestro. Sin embargo es necesario aclarar un fleco, la nota final referente a la localización exacta del espacio ocupado por los palcos ${ }^{41}$, y que hay que considerar como un añadido posterior tanto por su contenido como por su letra que responde a una grafía diferente.

Queda entonces pendiente la cuestión de lo realizado por Miguel Antonio García y Bouzas de Castro. El 18 de mayo, Fernández Busto muestra su disconformidad con el "mapa" enviado y solicita «se añada en el la expresión de el Parage, en que pretende tener posesión el Hospital, y su longitud, distinguiendose con el numero competente para poderlo hacer demostrable, de modo que no quede duda). Incluso ve conveniente se le envíe «otro Plan con esta circunstancia», por no estar comprendida en el anterior y ser el motivo fundamental de la controversia. Muy rápida tuvo que ser su elaboración ya que, el 15 de junio, el mapa estaba en Madrid. Este plano, que no ha sido hallado, sería, según las propias palabras del autor, «un diseño, en perspectiba de la Plaza del Obradoyro para mejor ynteligencia, con los edificios que en ella ay ${ }^{42}$ por el que se abonarían 150 reales de vellon el 25 de junio. En este diseño se deberían constatar, por una parte, el motivo solicitado desde Madrid referente al lugar reclamado por el Hospital con su longitud y número indicativo (que es lo añadido en el plano estudiado con las letras C y D, pero que en la nota final de la explicación figura sin la longitud ni el número exigido), y, por otra, aquel detalle mencionado por el prelado en su informe de 30 de mayo de 1747 sobre el lugar ocupado con anterioridad por la ciudad en el lateral que va desde las

\footnotetext{
${ }^{41}$ «Nota // el sitio que disputa el Real Hospital con la Ciudad esta en la talanquera que esta ocupa señalada con la letra $X$ y ba señalado entre la letra $C \ldots . . D$ frente a la letra $A$...B».

${ }^{42}$ A.H.U.S., Fondo del Ayuntamiento. Libros de Consistorios, Mayo-Junio 1746, fol. 194.
}

"CUADERNOS DE ESTUDIOS GALLEGOS", Tomo XLII, Fascículo 107, Santiago 1995. 
cadenas del Hospital hasta el Colegio de San Jerónimo (señalado en el mapa que tuvo delante con las letras C y D). Sin embargo, hay otros detalles reseñados en el dicho informe que llaman nuestra atención por tener su exacta correspondencia en el plano de Moas como son: los balcones del Colegio de San Jerónimo señalados con «las letras U», las dos columnas de entrada al Hospital con «las letras $A$ y $B$ », el balcón izquierdo del Hospital que ocupa el espacio existente entre «las letras $C y P$ » y el toril situado en el lugar marcado con «las letras $D$ y $G$ » de la fachada del Palacio Arzobispal. Estas coincidencias, la rapidez de su ejecución y su precio hacen posible la conjetura de que García y Bouzas de Castro tuviera presente el mapa de Francisco das Moas para su diseño.

La ausencia de datos de identidad tanto en el plano como en la explicación posiblemente se deba a que estemos ante las copias y no ante los originales.

Ahora bien, aunque el fundamento del plano haya sido el esclarecimiento de la controversia mantenida entre la ciudad y el administrador del Hospital Real, en él se representa la configuración de la plaza, sus dimensiones y los edificios que la delimitan y ocupan, acrecentando con ello considerablemente su valor.

Al norte limita con la enorme fachada del Hospital Real, al sur con la fachada del Colegio de San Jerónimo y una línea de casas, al este con el Palacio Arzobispal, fachada occidental de la Catedral y lienzo del Claustro, y al oeste con las cárceles eclesiástica y seglar, la cortaduría de carne y la muralla. Estos edificios y las calles que desembocan en ella, Franco, Inferniño, Huertas, San Francisco y Azabachería contribuyen a configurar su fisonomía de plaza "mayor". Su planta tiende a rectangular pero, eso sí, irregular, con constantes entrantes y salientes. No es una plaza de plataforma única sino que tiene acusados desniveles.

Muchas son las aportaciones del plano, unas servirán para corroborar la información entresacada de fuentes escritas, y otras, no tan conocidas, quedarán desveladas abriendo nuevos cauces a posteriores investigaciones. La primera se centra en las dimensiones de la plaza y los edificios y calles que la configuran. Tanto en el plano como en su explicación las medidas de la plaza vienen dadas en varas. Su longitud desde las columnas del Hospital Real hasta la pared del Colegio de San Jerónimo es de 110 y su anchura, sólo para este lateral, desde el Palacio Arzobispal al final del mirador es de 102.

La fachada del Palacio Arzobispal tiene una longitud de 31 varas hasta su estribo. Este lienzo está dividido en cinco pisos: el primero dominado

"CUADERnOS DE eStudios GALLEGOS", Tomo XLII, Fascículo 107, Santiago 1995. 
por la puerta de carros y tres ventanales, los dos siguientes por cuatro ventanas, el cuarto es liso y el último ha pasado de ser un balcón corrido con puertas y ventanas - dibujos de Vega y Verdugo (Fig. 2) - a ser una galería abalaustrada. El estribo sobresale 3 varas y tiene un ancho de 5 varas. A continuación aparece reflejada la confluencia de dos calles, una que asciende por debajo del arco del Palacio del Arzobispo y que se dirige a la Plaza del Campo, es la Azabachería, y otra flanqueada por los lienzos del Hospital Real y Palacio Arzobispal en el que se destaca un balcón, la de San Francisco, que va a la Puerta del Postigo. Su anchura es de 9 varas.

La fachada principal del Hospital, de 78 varas de longitud, está ordenada por dos ejes, por una parte, su ornamentada portada dispuesta en su centro, y por otra, sus dos barrocos balcones debidos a la reforma de $\mathrm{Fr}$ Tomás Alonso. El piso inferior, de 9 varas de altura, está articulado por una faja, una puerta plateresca dispuesta en un extremo y por cuatro tragaluces. En el superior dominan los dos balcones de hierro y sus cuatro puertas, una de traza clasicista y las restantes barrocamente revestidas. Esta fachada está precedida por un "patio" de 9 varas, delimitado por encadenadas columnas de diferentes tamaños. En el extremo que mira a la calle de las Huertas aparece un mirador de 21 x 17 varas de superficie. Para conocer la historia de este "patio" y mirador hay que remontarse al siglo XVI, momento en el que el Hospital solicita permiso al Ayuntamiento para construirlos. En julio de 1532, este último no encuentra inconveniente en donarle la superficie de 21 pies siempre que cumpla determinadas obligaciones: la construcción de un conducto de agua, de una nueva puerta en la muralla y del empedrado de la calle que conduce a San Francisco. Incluso plantea la posibilidad de los postes de piedra unidos por cadenas ${ }^{43}$. De gran trascendencia se puede considerar la instancia que hacen tres representantes del Hospital, Pero de Leon, administrador, García Prego, mayordomo y Juan López de Salazar, capellán mayor, en el pleno municipal del 5 de julio de 1550, planteando que «se deshiziese una torre de la cerça de la dha çiudad frontero del patio y encadenado del dho hospital que quita la bista y haze muy perjuizio a la dha casa e patio y se despejase la plaza de toda la tierra acumulada que ya superaba en altura el pation. Estos inconvenientes junto con el mal estado de la Puerta de la Trinidad y su camino, «muy fondido y echo de tal manera que con gran pena se andaba por el»,

\footnotetext{
${ }^{43}$ ¿A.H.U.S. Fondo del Hospital Real, General n $1973-391$.
} 
fueron determinantes en la concesión del Ayuntamiento sobre la reducción de la torre y ampliación, sobre arcos, de la lonja hasta la muralla. El Hospital, a su vez, tenía las siguientes obligaciones: cerrar la puerta de la Trinidad igualando su terreno con el de la puerta de «serbentia» del Hospital; abrir, enfrente del obradoiro de la Catedral, una nueva puerta cuyo arco tenga la misma altura que la vieja de la Trinidad y supere en tres pies su anchura; nivelar la plaza hasta la escalera y puerta nueva. E1 resto de la plaza, desde las escaleras hasta las casas de Jácome Montaos, correría por cuenta de la ciudad ${ }^{44}$.

En las inmediaciones del patio se encuentra una escalera de $2 \frac{1}{2}$ varas de ancho que desciende hasta el nivel de la Puerta de Carros del Hospital. A continuación está una puerta peatonal denominada Falsa que permite salir fuera del recinto amurallado. Esta puerta y las escaleras debieron ser construidas por el Hospital debido a que era el camino empleado para conducir los muertos al cementerio situado en las proximidades, extramuros de la ciudad. Siguiendo la muralla hacia las cárceles nos encontramos con la abovedada puerta de las Huertas, construcción mencionada a mediados del siglo XVI y que debido a su gran tamaño permitía el acceso de animales, carros y caballerías. De ella parte un camino por el cual se puede ir a la Puerta de Carros del Hospital o a la parte superior de la plaza, pasando por delante de las cárceles eclesiástica y seglar y desembocando en la fachada del Colegio de San Jerónimo. También existe otro camino en el lado sur, entre una hilera de casas y la cárcel eclesiástica, que conduce a la muralla.

La construcción que está ubicada entre la cárcel seglar y la puerta de las Huertas ha sido considerada como la carnicería que el arquitecto Domingo de Andrade trazó en torno a 1701. La base para tal afirmación ha sido el plano de Miguel Ferro Caaveyro, donde aparece un edificio bajo la denominación de carnicería provisional (Fig. 5). Pero esta prueba "de doble filo" nos sirve para afirmar justamente todo lo contrario, este edificio no es el construido por el afamado arquitecto barroco, ya que la comparación de las plantas mostradas por cada uno de ellos permite comprobar que no hay una correspondencia. La construcción plasmada por Caaveyro tiene planta rectangular, su fachada principal mira a la plaza y su pared posterior se adosa a la muralla. Sin embargo, la planta de Andrade es trapezoidal y la pared paralela a la entrada tiene seis ventanas. Por otra parte, la carnicería

${ }^{44}$ A.H.U.S. Ibidem, n $1973-394$.

"CUADERNOS DE ESTUdIOS GALLEGOS", Tomo XLII, Fascículo 107, Santiago 1995. 
de Andrade posiblemente fuese construida en la zona denominada "la Pescadería", pues así se recoge en la leyenda de su planta: "Planta para la Carneçeria desta ciudad; sitio en la Pescadería"45. Una vez aclarado este dilema, falta por saber qué era este edificio. En la documentación del siglo XVIII aparece bajo distintos nombres pero compartiendo una característica común, el abasto de carnes; un "posito» para el abasto de carnes ${ }^{46}$, posteriormente como carnicería ${ }^{47} \mathrm{y}$, en el plano de Moas, como «cortaderia de carne». Por lo tanto no es de extrañar que en el plano de Miguel Ferro Caaveyro se denomine carnicería provisional.

La ubicación de la Cárcel en esta plaza viene de muy antiguo, pero su configuración ha variado a lo largo del tiempo. En la documentación del siglo XVI aparece con los nombres de «Torre de la Plaza o carcel del Señorio» y «torre mayor, cárcel del Arzobispo» y en el plano de este siglo aparece un edificio de planta cuadrada denominado cárcel (Fig. 1). Por lo que respecta a la cárcel pública no se sabe la fecha de construcción, pero sí que estaba junto a la cárcel eclesiástica en la segunda mitad del siglo XVII y que ambas sobresalían por encima de la muralla, como se puede apreciar .en el dibujo del Viaje de Cosme de Médicis (Fig. 3). Su lamentable estado y continuas reparaciones es una constante en los documentos del siglo XVIII ${ }^{48}$. En el Consistorio de 22 de abril de 1730 se decide confeccionar las

${ }^{45}$ TAÍN GUZMÁN, M., Andrade tracista, Santiago 1993, págs. 19 y 32.

${ }^{46}$ El regidor, D. Francisco Javier Nabarrete, tiene que asistir en el pósito para el abasto de carnes que se halla junto a la cárcel seglar. Cf. A.H.U.S. Fondo del Ayuntamiento. Libros de Consistorios, $3^{\text {er }}$ Trimestre 1733, fol. 377v.

${ }^{47}$ Tomás de Fontenla, maestro de carpintería, señala en su reconocimiento de la cácel seglar que en la cocina hay una ventana que «dize para la parte de la carniceria». Cf A.H.U.S. Ibidem, Septiembre-Diciembre 1744, fol. 44r.

${ }^{48}$ «Digo yo Lucas Antonio Ferro Caaveyro Maestro de obras y Aparejador de las de la Santa Apostolica y Metropolitana Yglesia que de orden de su mrd. el Señor D. Francisco Xavier Nabarrete Alcalde mas antiguo de esta Ciudad e bisto y reconozido un abujero echo a mano en la puerta de uno de los Calabozos ynteriores que tiene la Carzel Real de dha Ciudad cuio rompimiento se hizo con esta de madera y arrimado al marco de madera que tiene la puerta de dho Calabozo; Y asi mismo e bisto otro rompimiento de quatro quartas de largo y dos quartas de alto en otro calabozo ymediato al referido y en la pared exterior que haze frente al Cementerio del Real Hospital cuio rompimiento tambien se hizo con ynstrumentos de madera como lo reconozio el que declara por las señales de las abolladuras que en dhos rompimientos ha encontrado. Tubo de coste el cerrar los expresados rompimientos de cal pizarra y trabajo del oficial doze rreales de vellon y lo firmo Santiago y Febrero 3 de 1747». Cf. A.H.U.S., Ibidem, $1^{\text {er }}$ Trimestre 1747, fol. 284 .

"CUADERNOS DE ESTUDIOS GALLEGOS", Tomo XLII, Fascículo 107, Santiago 1995. 
plantas para fabricarla de nuevo. El autor es el P. Maestro Belasco ${ }^{49}$. Sin embargo, las obras no debieron llevarse a cabo ya que en 1733 y 1744 sigue totalmente arruinada. El plano de Francisco das Moas nos presenta el alzado de estas dos edificaciones, que no destacan precisamente por su valor arquitectónico, señalando que la cárcel que tiene su fachada principal orientada hacia el Hospital es la Seglar y la encarada con el Claustro es la Eclesiástica. En el medio de ambas aparece un patio cerrado por un muro "almenado". El conocimiento de sus plantas se obtiene a partir de los planos de la década de (Fig. 4) 1750, y de Miguel Ferro Caaveyro (Fig. 5). Los reconocimientos hechos en la cárcel seglar permiten conocer algunas de sus dependencias: capilla, cuarto del carcelero, cocina, torre y calabo$\operatorname{zos}^{50}$.

Una hilera de casas pertenecientes a la Universidad y el Colegio de San Jerónimo componen el cierre sur de la plaza. El frente del Colegio es de reducidas dimensiones, 34 varas, y en su delantera también posee una lonja de 3 varas de ancho perfilada por pilares. La puerta principal es el eje de su simétrica fachada en la que destacan dos balcones. Contigua al colegio está una calle de 13 varas de ancho que se dirige al Franco.

Cerrando la plaza por el este se dispone el lienzo del Claustro con dos puertas y la escalera de acceso a la Iglesia cuya longitud es de 18 varas y su anchura de 14.

Otras aportaciones como pueden ser la plaza de toros y el "castillo de fuego" permitirán analizar su carácter escenográfico. El coso, dada su eventualidad, era de gran simplicidad. No era exento, sino que aprovechaba como parte de su cierre los edificios que están determinando su anchura, el flanco este y el "castillo de fuego", y su longitud, las lonjas del colegio de San Jerónimo y del Hospital Real, teniendo en cuenta que entre las cadenas del Hospital y el tablado debería dejarse un camino de tres varas de ancho. El resto del cierre estaba compuesto por dos vallas de madera con un camino intermedio, posiblemente ocupado por espectadores, formando una plaza rectangular. Este palenque tenía tres puertas portátiles ubicadas en los extremos, una servía de comunicación con la calle del Franco, otra de $10 \times 10$ cuartas permitía el acceso a la puerta principal del Hospital y la tercera, empleada por la ciudad para entrar y salir, estaba dispuesta en las

${ }^{49}$ Se le pagaron 480 reales por las plantas de la cárcel pública y las de las fuentes de S. Miguel y Torreón de Mazarelos. Cf. A.H.U.S. Ibidem, Junio-Diciembre 1730, fol. 471.

${ }^{50}$ A.H.U.S. Ibidem, Enero-Abril 1746 fol. 336 y $1^{\text {er }}$ Trimestre 1747 fols. 283-284.

"CUADERNOS DE ESTUdiOS GALLEGOS", Tomo XLII, Fascículo 107, Santiago 1995. 
inmediaciones del Palacio Arzobispal. En el espacio comprendido entre el castillo de fuego, el Hospital Real y el Palacio Arzobispal se disponían las talanqueras cuya altura alcanzaba 4 varas. Pero esto no había sido siempre así, según declara el Arzobispo. Antes no había tablados delante de la fachada del Hospital, la ciudad sólo ocupaba el espacio que se extiende desde el patio del Hospital hasta el Colegio de San Jerónimo y este último había encargado, algunas veces, a sus carpinteros la ejecución de tablados en la delantera de su fachada. Incluso el espacio existente entre el tablado y las cadenas la considera perjudicial ya que esta separación dificulta más la visión que si estuviera contiguo.

En el plano se reflejan algunos detalles del engalanado palco. En su delantera tiene balaustres y "pontones» que sirven para cubrirlo con toldos; a través de la documentación sabemos que el acceso era por escaleras y que estaba ocupado por ocho bancos de respaldo cubiertos de terciopelo, un dosel para el retrato del Monarca, en este caso Felipe $V$ de cuerpo ente$\mathrm{ro}^{51}$, colgaduras y tapicerías. El sitio elegido para el toril es en el ángulo del Palacio Arzobispal. También aparecen los volados balcones y "loggias" de los distintos edificios desde donde sus comunidades e invitados, como espectadores privilegiados, presenciaban los festejos. En los balcones del Hospital se constata la presencia de los religiosos de San Agustín y colegiales del Colegio de los Irlandeses. Igual afluencia de gente había en los demás balcones del Palacio Arzobispal, del Cabildo, del Colegio de San Jerónimo y en otros asientos dispuestos en la plaza.

Para la celebración de estas fiestas se realizaban arquitecturas efimeras, así hay que considerar el "castillo de fuego", cuya quema es otro acto intrínseco del homenaje al Apóstol. Dispuesto en el centro de la plaza y ocupando gran espacio se nos presenta como una estructura arquitectónica de forma piramidal compuesta por un pedestal y cuatro niveles decrecientes con veinte huecos. Su contrata corría por cuenta del Cabildo catedralicio. Este año, al igual que en años anteriores, uno de los encargados de su realización fue el pintor Juan Antonio de Bouzas ${ }^{52}$ cuyo trabajo consistía

${ }^{51}$ El precio de este retrato ascendió a 120 reales de vellón. Cf. A.H.U.S. Ibidem, $1^{\text {er }}$ Semestre 1704, fol. $49 \mathrm{v}$.

52 «Digo yo Juan Antonio Garcia de Bouzas Pintor que recivi del Sr. D. Manoel Antonio Posse Canonigo Fabriquero... quinientos y cinquenta rs de vellon por el trabajo de dibujar y asistir a las pinturas del Castillo que se a echo este año Santo. Santiago 23 de Julio de 1745.» Cf. A.C.S. Fabrica, Comprobantes de Cuentas 1744-1745, Caja B.

"CUADERNOS DE ESTUDIOS GALLEGOS", Tomo XLII, Fascículo 107, Santiago 1995. 
en dibujar y pintar los lienzos que cubrirían los huecos. Al mismo tiempo se contrataba con un cohetero los fuegos de artificio que llevaba el Castillo. Domingo Antonio Canzela y Troncoso fue el elegido ${ }^{53}$.

El trazado irregular de la plaza ha sido la tónica dominante, con entrantes y salientes permanentes. Al mismo tiempo, sus distintos niveles aparecen reflejados claramente en nuestro plano en el camino que conduce desde la Calle de las Huertas (Fig. 7) ${ }^{54}$. Éste es de por sí una constante pendiente que se agudiza en el acceso a la plaza por un tramo de escaleras, cubierto por un arco «últimamente restaurado», que es la denominada "Puerta Falsa"55. Una vez en el interior del recinto amurallado nos encontramos en una pequeña plataforma flanqueada por la muralla propiamente dicha y por un zigzagueante muro, posiblemente de contención. La existencia de éste en la plaza viene de antiguo, pues en el plano del siglo XVI ya se recoge (Fig. 1). Con posterioridad, en 1607 y 1608, se describe como un muro torcido ubicado enfrente de la puerta de la Catedral, delante de la torre y que sale al Hospital. El cabildo y ayuntamiento se ponen de acuerdo para enderezarlo evitando así la fealdad y desproporción que causaba ${ }^{56}$. En nues-tro acceso hacia la plataforma superior, dejando a la izquierda la puerta de Carros del Hospital, podemos elegir entre continuar de frente por una escalera de dos tramos cercana al mirador o ascender por la rampa que desemboca en la delantera del colegio de San Jerónimo y que a su vez tiene otra escalera a la altura de la cárcel seglar. Otro de los accesos existente en este amurallado flanco occidental es la puerta de las Huertas cuyas dimensiones permitían la entrada de los animales y carros a la plaza. Por último no debemos olvidarnos de la rampa que desemboca en la calle del Inferniño.

${ }^{53}$ Véase apéndice documental $n^{0} 3$. Cf. A.C.S. Ibidem.

${ }^{54} \mathrm{El}$ "alzado" que se presenta ha sido elaborado teniendo como base distintos planos: el de Francisco das Moas, el anónimo del siglo XVIII y el de Miguel Ferro Caaveyro. Creíamos conveniente su realización por la claridad que podía aportar en la comprensión de la plaza.

${ }^{5 s}$ «el pequeño arco por donde pasan casi todos los dias los entierros al campo santo se arruina por lo qual pasan los capellanes, y demas gente con mucho recelo, y me an pedido que le haga desmontar y componer el paso, suponiendo estar dentro de los limites de esta Real Casa, y que se hizo de su quenta...». No sólo era paso para los muertos sino también tránsito frecuentado por los vivos. Cf. A.H.U.S. Ibidem, Enero-Mayo 1741, fol. 54.

${ }^{56}$ GOY DIZ, A., Op. cit., pág. 1.327; A.H.U.S. Ibidem, 1605-1614, fol. 101r; A.C.S. Actas capitulares, libro XXII, fol. 404r.

"CUADERNOS DE ESTUDIOS GALLEGOS", Tomo XLII, Fascículo 107, Santiago 1995. 


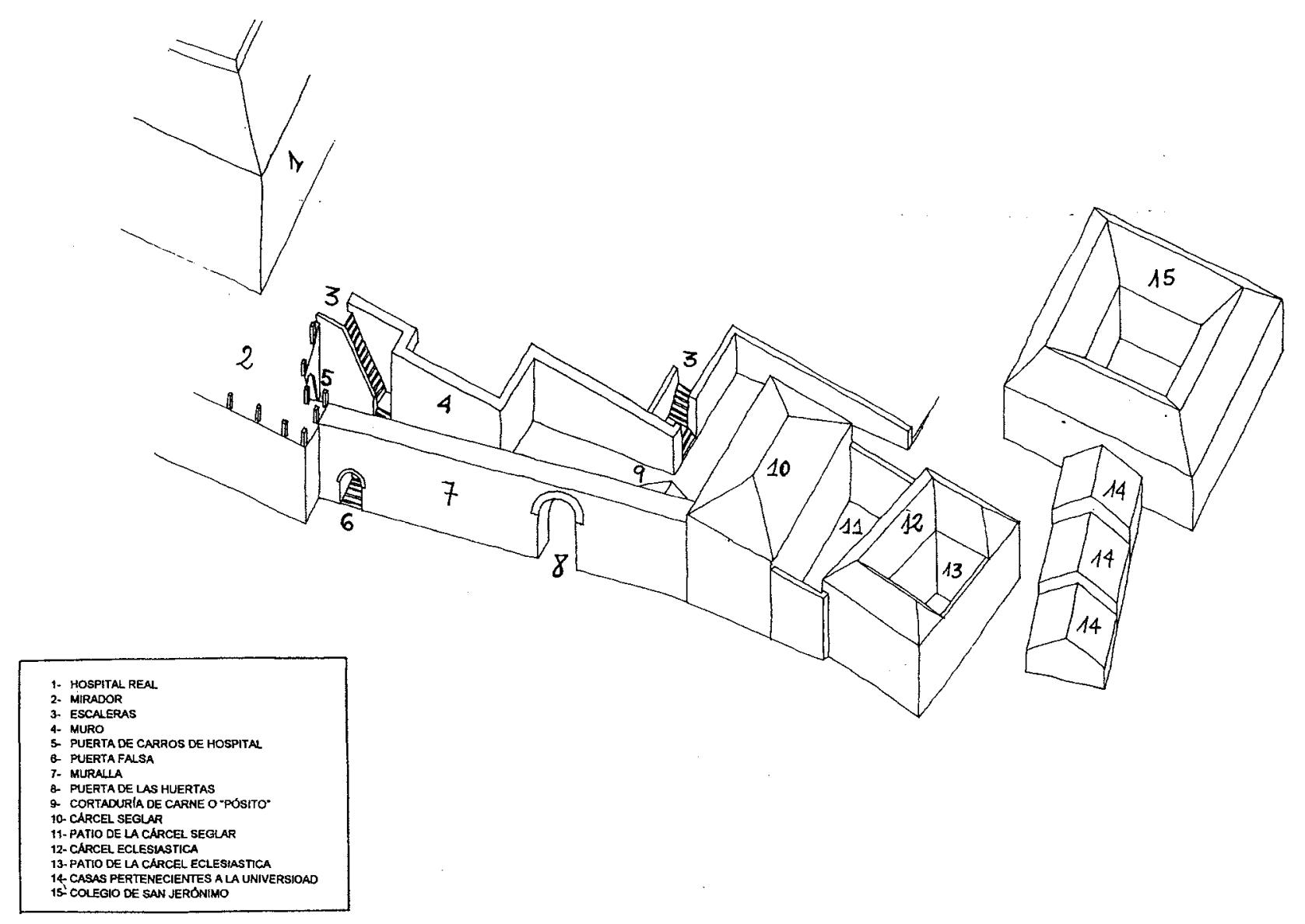

Figura 7. Alzado del cierre occidental de la plaza del Obradoiro. 
Esta topografia sufrió una radical transformación al llevarse a cabo el proyecto de Seminario de Confesores, Cárceles secular y eclesiástica y Consistorio que, según las trazas del ingeniero Carlos Lemaur, se comenzó en $1767^{57}$. Con su erección quedó configurado uno de los espacios más emblemáticos del urbanismo español (Fig. 8). El carácter espectacular de la plaza del Obradoiro la ha convertido en el foco de atracción de peregrinos y turistas, al mismo tiempo que en el escenario por antonomasia en el que transcurren y se desarrollan los actos más significativos de las celebraciones anuales del Apóstol Santiago, como son las celebraciones religiosas (eucaristía), lúdicas (conciertos, fuegos de artificio) y simbólicas (quema de la fachada).

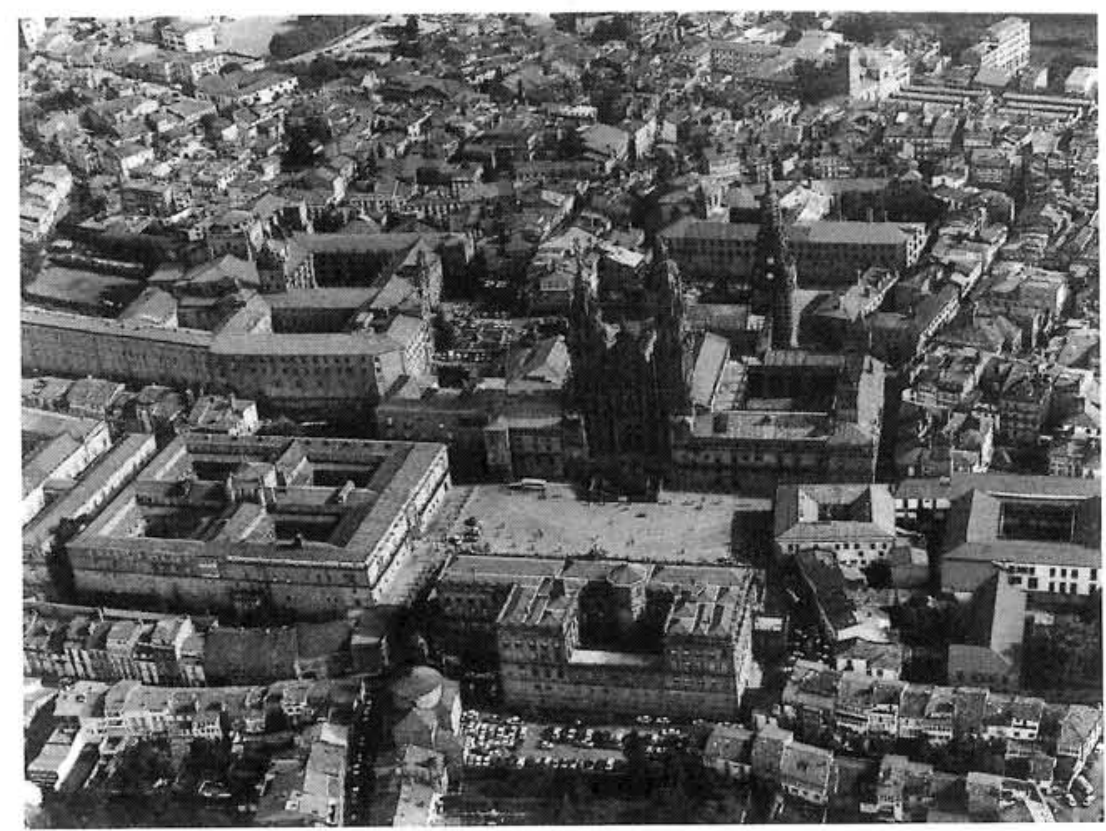

Figura 8. Vista aérea de la plaza del Obradoiro.

${ }^{57}$ Sobre la historia de este edificio véase los siguientes artículos: PÉREZ COSTANTI, P., "Las Casas Consistoriales de Santiago" en Notas Viejas Galicianas, 1925, T. II, págs. 189-203; ORTEGA ROMERO, M.S., "Noticias sobre la construcción del Ayuntamiento de Santiago de Compostela", C.E.G., Santiago 1966, págs. 81-101; VIGO TRASANCOS, A., "La intervención del estado dieciochesco en la arquitectura gallega de iniciativa privada: el papel de los ingenieros y la obra de Carlos Lemaur", C.E.G., Santiago 1992, págs. 103-133.

"CUADERNOS DE ESTUDIOS GALLEGOS", Tomo XLII, Fascículo 107, Santiago 1995. 


\section{APÉNDICE DOCUMENTAL}

\section{$\mathbf{N}^{0} 1$}

La primera que ha de hacer los cortijos, o casetas de madera contra la pared del palacio del Yllmo. Señor Arzobispo, a la yzquierda bajando por bajo el arco de dho Palacio segun lo practica estilo y costumbre vien seguros para recoxer quatro toros, separadamente uno de otro porque no se hagan daño.

La segunda que ha de cerrar de buena madera fuerte y segura con clavazon toda la plaza del obradoiro en las partes que lo necesite, y asegurada de tal manera que los toros no agan fuga ni a las gentes subcedan disgracias.

La tercera que para el asiento en que ha de estar la Ciudad y el quadro del retrato de S.M. bajo el docel ha de acer en el terreno y sitio acostumbrado delante las colunas que dividen de la plaza, el enlosado del Real Hospital tablado fuerte y seguro y donde puedan estar como siempre estubieron ocho bancos de respaldo, cubiertos de terciopelo encarnado, los mismos que estan en la Sala consistorial para estar sentados los Señores Alcaldes, Capitulares Secretarios de Ayuntamiento y personas del cuerpo de la Ciudad.

La quarta que se ha de apartar, como siempre se hizo de las colunas de dho enlosado tres baras que hacen doce quartas de manera que por este ambito puedan andar y transitar gentes, carros, y cavallerias, asi para la Calle de las Guertas, Taras, la de San Francisco, y la de vajo de Palacio para la plaza, de cuia forma que son la unicas calles de alli, que da todo el andamio en libertad, como tamvien lo que quedan todas las puertas de Real Hospital, asi la principal; la que llaman del Postigo; y otra que está abajar las escaleras del Patio que dice a dha Calle de las Guertas.

La quinta que ha de acer para las entradas y salidas de dha plaza tres puertas portatilis la una junto a la pared del Palacio del Yllmo. Sr. Arzovispo, por donde a de entrar y salir la Ciudad; y la otra fuera de dhas Colunas de enlosado del Real Hospital frente a la puerta principal, pero apartado de dhas colunas las tres varas expresadas en la quarta condicion, y otra ynmediato al Colexio de San Geronimo en medio de el y de la pared donde está el balcon de la Sala Capitular de la Santa Yglesia de Señor Santiago, $y$ an de estar francas y aviertas y solamente cerradas mientras se haga la corrida y no mas. 
La sesta que la puerta portatil que queda señalada en la quinta condicion que diga frente a la puerta principal del Real Hospital y en el terreno de la plaza, desviado las tres varas de las Colunas y Cadenas, a de tener de ancho diez quartas, y de alto otras tantas poniendo encima de ella tablados en la manera que siempre se acostumbro con cerramiento senzillo sin faltar al que corresponde hazerse para el retor y colexiales del Colexio de San Clemente de Pasantes, por no tener alli valcones y a de estar en el sitio acostumbrado de dha plaza.

La septima condicion es que segun la costumbre y aun estrechandose la altura del asiento en que ha de estar la Ciudad fixado en el terreno, a de ser de quatro baras que son diez y seis quartas, de cuia manera teniendo como tienen los valcones del Real Hospital desde sus barandillas hasta el pabimento de avajo, de altura nueve baras vien cumplidas, les queda de elebacion sobre los tablados de la Ciudad para la plaza, cinco baras que hacen veinte quartas, no se puede embarazar, ni embarazará la vista de dhos valcones, antes vien de esta suerte predominan al asiento, quedando este devajo de ellos y separadamente libre y franco el enlosado de entre colunas a paredes del Hospital que tiene nueba varas de ancho, y ademas de ello quedan a mejor beneficio de mas ambito y anchura las tres varas en el terreno de la plaza a fuera de dha colunas y entre ellas a las talanqueras para que se pueda transitar con franqueza y sin el menor embarazo como queda explicado en la quarta condicion sin recibir de esta forma el Real Hospital ni el comun daño ni perjuicio alguno ademas de la corrida de toros nunca se detiene mas de asta dos oras.

Con cuias condiciones y no sin ellas el Señor Alcalde mas antiguo hace el remate de dho cerramiento y asientos al expresado Francisco Rodriguez, en los ciento setenta y seis reales que se le han de dar y pagar. 


\section{$\mathbf{N}^{\circ} 2$}

Descripción de las medidas que he tomado de la plaza del obradoyro cita en esta ciudad de Santiago con sus entradas y salidas que esta ynclusa entre la Iglesia Catedral de Santiago Palacio del Arzobispo, Ospital Real, Colegio de San Geronimo y Muralla que debide la Calle de las Guertas; la muralla por la parte que debide la plaza mira a la Iglesia Mayor, y palacio del Arzobispo, y estos miran al poniente por la misma parte que dibiden la Plaza, El Colegio de San Geronimo tambien por la parte que termina la plaza mira al trabesio y ospital tambien por el termino de la Plaza mira al solano, en cuya discripcion se señalan la baras de ancho largo de dicha Plaza, y las de las Calles que pasan por ella; como tambien el de las escaleras que bajan de la Cathedral a dha plaza ancho del Patio de las Cadenas del Ospital; largo del mirador; y colunnas; como tambien del Alto de la solana del Ospital, y talanqueras en que se pone el Retrato de Nuestro Rey D. Phelipe Quinto, que Dios guarde, y la Señora Ciudad lo qual todo declare por las Letras del Abezedario segun aqui las apuntare; como tambien en la ynsignacion del Plantado de dha Plaza para que asi se pueda conocer el ancho largo de cada cosa=

Primeramente la Plaza tiene de largo desde el Pattio de las Colunas del Ospital asta la pared del Colegio de San Geronimo ciento y Diez baras las que señalo con la letra A

Mas el Palacio del Arzobispo que esta unido a la escalera de la ssta. Iglesia tiene de largo asta un estribo, treynta y una baras que señalo con la letra

E ynmediato a las escaleras en esta misma cantidad esta una puerta que llaman de Carros que señalo con la misma letra B

El dho estribo de Palacio tiene de salida, a la Plaza tres baras y es donde aze la Señora Ciudad el Toril para los toros que señalo con la letra ...... C

De ancho el estribo tiene cinco baras que señalo con la letra ............. D

Ynmediato a dho estribo para una calle por devajo de un arco que, hes del mismo Palacio que Camina a la Plaza del Campo que tiene de ancho cinco baras que señalo con la letra

En linea con el mismo Palacio pasa una calle que ba derecha a San Francisco y Puerta del Postigo que dice por el costado con el Ospital Real tiene de ancho nuebe baras que señalo con la letra F

\footnotetext{
"CUADERNOS DE ESTUDIOS GALLEGOS", Tomo XLII, Fascículo 107, Santiago 1995.
} 
Bajando por la Calle que biene por devajo del Palacio que ya, ynsinuee esta el Ospital Real a la mano derecha el que tiene por la frontera que dice a la Plaza, setenta y ocho baras de largo que señalo con la letra G

En el medio de, esta cantidad, esta la Puerta principal y dice cada una de las partes divide su balcon de yerro, y cada uno tiene dos puertas que bienen saliendo a ellos los que señalo con la letra

\section{I}

Desde un Patio que ay delante del Ospital al balcon ay nuebe baras de alto que señalo con la letra

En la cantidad de la altura de dho balcon no ay bentana alguna solamente unos tragaluces pequeños con unas rejas de yerro, como tambien uno que esta sobre la puerta principal que señalo con la letra.....

El patio que esta delante del ospital de ancho desde la pared asta las colunas que tienen una cadena, nuebe baras que señalo con la letra ....... L

$\mathrm{Y}$ en la parte de avajo de dho Patio ay un mirador que mira a la Calle de las Guertas su largo es veynte y una baras que señalo con la letra ........ M

$\mathrm{Y}$ de ancho dho mirador tiene diez y siete baras que señalo con la letra

Y las colunas que estan delante del dho Patio con su cadena cada una de las mayores tiene alto tres baras, y palmo, y cada una de las menores tiene de alto una bara y tres palmos las quales todas señalo con la letra ......... O

Y por la parte de avajo del Ospital ynmediato a las colunas sale una escalera que baja por debajo de un arco de la muralla que baja a la Calle de las Guertas que tiene de ancho dos baras y media que señalo con la letra

Mas adelante esta otra puerta de muralla a la qual viene el camino por delante de las Carzeles eclesiastica y seglar las que como tambien la puerta señalo con la letra e (Q)

Mas adelante ba otro camino que dice de miembro con las Carcel eclesiastica que ba a las murallas que señalo con la letra ... R

Mas adelante esta el Colejio de San Geronimo que tiene de largo treynta y quatro baras que señalo con la letra $\mathrm{S}$

$Y$ un patio que sale a dha plaza tiene de ancho tres baras que señalo con la letra $\mathrm{T}$

$Y$ en medio de la cantidad del largo esta la puerta principal y cada una de las partes tiene su balcon y en cada una su puerta que señalo con la letra ... V

Ynmediato a dho Colegio por el costado de arriba que compite con la Yglesia mayor pasa una calle que camina al franco tiene de ancho trece baras las que señalo con la letra..... $\mathrm{X}$ 
En la sera de la Yglesia mayor se hallan dos puertas en donde se estan operando otras para la dha Santa Yglesia que señalo con la letra .......... Y

En el medio del Largo de dha plaza esta una escalera que biene de la Santa Yglesia del Señor Santiago que es la puerta principal de ella y tiene de un estribo al otro que dividen en las puertas Diez y ocho baras, que señalo con la letra

Y de salida a la plaza tiene catorce baras que señalo con la misma letra

Mas abajo de dha escalera en la linea del centro de dha Plaza se hace un Castillo de fuego el dia del Santo Apostol, y uniendo con dho Castillo cierra la plaza toda la Señora Ciudad de madera, y en la parte que dice de espaldas contra el Ospital se pone el trato de Nro. Rey D. Phelipe Quinto que Dios guarde, y en el mismo sitio junto a dho rretrato se pone la Señora Ciudad, y la altura de las talanqueras o tablado es de quatro baras de alto, que todo señalo con el numero Diez Romano

$Y$ entre las colunas del Ospital, y talanqueras pasa una calle que tiene de ancho dos baras que señalo con el numero cinco Romano ................. V

La linea que ba de encarnado es el castillo y cerramiento de la Plaza y toda la sombra de negro es calle y por ser verdad lo firmo a Diez y siete de Nobiembre de mil setezientos y quarenta y cinco $=$

Nota // el sitio que disputa el Real Hospital con la Ciudad esta en la talanquera que esta ocupa señalada con la letra $\mathrm{X}$ y ba señalado entre la letra C...D frente a la letra A...B... 
Memoria del fuego que entrego Domingo Antonio Canzela y se gasto en el Castillo de la fiesta de Nuestro Sagrado Apostol Señor Santiago este año Santo de 1745.

Ducientas, y veynte varas, de fuego, luminado con tronadores, a quatro reales y dez mrs la bara, hazen nuebe cientos quarenta y quatro reales y veinte y quatro mrs.

Quatrocientas varas de tronadores, las ducientas y cinquenta com brevas dobles, a tres reales y medio la vara, son ochocientos setenta y cinco reales. $\mathrm{Y}$ las ciento y cinquenta de brevas hordinarias, a tres reales la vara son quatrocientos y cinquenta rểales vellon.

Mas ochenta varas de guias sencillas, a quince quartos hazen ciento y quarenta reales y diez mrs.

Mas ochenta varas de guias combrebas dobles y veynte y tres quartos son ducuentos diez y seis reales y diez y seis mrs vellon.

Mas ochenta brevas grandes a ocho reales y medio son seiscientos y ochenta reales vellon.

Veinte y nuebe espejos a diez y seis reales son quatrocientos sesenta y quatro reales.

Cubos sesenta y quatro; cada uno con tres coetes de luzes y otros tres de puga a cinco reales cada cubo son trescientos veinte reales.

El cubo grande con seis dozenas de coetes de Luzes a nuebe reales la do-

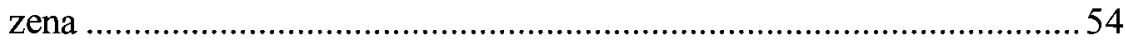

Los tres truenos grandes, a 22 rs cada uno .........................................66

Mas ocho ruedas cada una tenia ocho truenos, a diez rs cada una son ochenta rs.

Mas treinta y dos baras de fuego yluminado esto es solo la guia con su fuse sin breba a dos rs son sesenta y quatro

Las dos palmas de la plaza le añadio treynta y quatro rocas, las diez y ocho dobles, a siete rs son ciento veynte y seis rs vellon

Las diez y seis sencillas, a tres rs y medio ............................................56

La rueda de la palma grande con ocho, mangas, son treynta rs la rue-

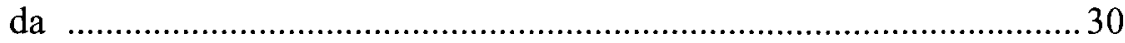

Ochenta guias para en guir son 40 rs.

Por manera que ymportan los fuegos quatro mil seiscientos y cinco rs y veninte y seis mrs los que recivi de mano del Sr. Canonigo Fabriquero D. Manuel Antonio Posse de Soto...lo firmo en Santiago Diziembre 23 de 1745.
\end{abstract}

"CUADERNOS DE ESTUdiOS GALLEGOS", Tomo XLII, Fascículo 107, Santiago 1995. 